\title{
Calcium-dependent conformational changes of membrane-bound Ebola fusion peptide drive vesicle fusion
}

\author{
Tatiana Suárez ${ }^{\mathrm{a}}$, María J. Gómara ${ }^{\mathrm{a}}$, Félix M. Goñi ${ }^{\mathrm{a}}$, Ismael Mingarro ${ }^{\mathrm{b}}$, Arturo Muga ${ }^{\mathrm{a}}$,

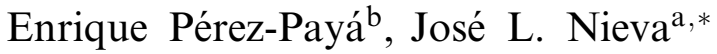 \\ ${ }^{a}$ Unidad de Biofísica (CSIC-UPVIEHU) y Departamento de Bioquímica, Universidad del País Vasco, Aptdo. 644, 48080, Bilbao, Spain

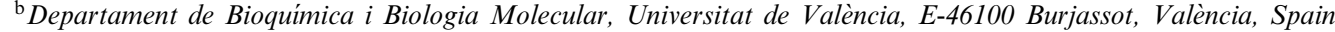

Received 1 October 2002; revised 20 November 2002; accepted 27 November 2002

First published online 19 December 2002

Edited by Hans-Dieter Klenk

\begin{abstract}
The fusogenic subdomain of the Ebola virus envelope glycoprotein is an internal sequence located ca. 20 residues downstream the $\mathrm{N}$-terminus of the glycoprotein transmembrane subunit. Partitioning of the Ebola fusion peptide into membranes containing phosphatidylinositol in the absence of $\mathrm{Ca}^{2+}$ stabilizes an $\alpha$-helical conformation, and gives rise to vesicle efflux but not vesicle fusion. In the presence of millimolar $\mathrm{Ca}^{2+}$ the membrane-bound peptide adopts an extended $\beta$-structure, and induces inter-vesicle mixing of lipids. The peptide conformational polymorphism may be related to the flexibility of the virus-cell intermembrane fusogenic complex.
\end{abstract}

(C) 2002 Federation of European Biochemical Societies. Published by Elsevier Science B.V. All rights reserved.

Key words: Ebola glycoprotein; Fusion peptide; Membrane fusion; Viral fusion; Peptide-lipid interaction

\section{Introduction}

Ebola virions are surrounded by a lipidic envelope containing a single type of a highly glycosylated protein (Ebola GP) that makes up the spikes protruding from the virion surface [1-5]. Several findings confirm that structural Ebola GP is responsible for receptor binding and membrane fusion during Ebola entry into the host cells [6-8]. Ebola GP is synthesized as a precursor molecule and subsequently cleaved by furin into two disulfide-linked subunits, surface (GP1) and transmembrane (GP2) that, similarly to other viral envelope glycoproteins, are arranged as trimers of heterodimers [4,5].

Gallaher [9] predicted the existence in GP2 of an internal fusion peptide of approximately 16 uncharged, hydrophobic residues. Subsequent experiments demonstrated that the sequence interacted with and fused lipid vesicles [10]. Partitioning of the peptide into bilayers required the presence of phosphatidylinositol that is conspicuously represented in the plasma membrane of the hepatocyte, one important viral target for Ebola infection [1]. Mutational analysis provided additional evidence supporting the role of the GP2 fusion peptide in the fusion process and viral infectivity [11].

In this contribution we have analyzed the energetics and structural requirements for interaction with lipid vesicles of

*Corresponding author. Fax: (34)-94-4648500.

E-mail address: gbpniesj@lg.ehu.es (J.L. Nieva).
$\mathrm{EBO}_{\mathrm{GE}}$, a peptide representing the Ebola fusion region. The structural characterization confirms that folding occurs in membranes containing phosphatidylinositol. Furthermore we observe that the peptide may exist in three different states, namely unbound random coil, membrane-bound $\alpha$-helix, or membrane-bound $\beta$-strand. The adoption of an $\alpha$-helical structure in the absence of $\mathrm{Ca}^{2+}$ appears to be related to the ability of the peptide to perturb membranes and cause permeabilization, whereas the $\beta$-structure is observed in the presence of $\mathrm{Ca}^{2+}$ under conditions leading to fusion. Thus, our data are consistent with the existence of structurally polymorphic states of membrane-bound Ebola internal fusion peptide. These findings provide information on the properties of the cell-virus intermembrane fusion complex.

\section{Materials and methods}

Phosphatidylcholine (PC), phosphatidylinositol (PI), and the fluorescent probes $N$-(7-nitro-benz-2-oxa-1,3-diazol-4-yl)phosphatidylethanolamine ( $N$-NBD-PE) and $N$-(lissamine rhodamine B sulfonyl)phosphatidylethanolamine ( $N$-Rho-PE) were purchased from Avanti Polar Lipids (Birmingham, AL, USA). 8-Aminonaphtalene-1,3,6-trisulfonic acid sodium salt (ANTS) and $p$-xylenebis(pyridinium)bromide (DPX) were from Molecular Probes (Junction City, OR, USA). $\mathrm{D}_{2} \mathrm{O}$, trifluoroethanol (TFE), $N$-acetyl-L-tryptophanamide (NATA) and Triton X-100 were obtained from Sigma (St. Louis, MO, USA). The sequence representing the putative fusogenic segment of Ebola GP, GAAIGLAWIPYFGPAAE, $\mathrm{EBO}_{\mathrm{GE}}$, was synthesized as its C-terminal carboxamide and purified (estimated homogeneity $>90 \%$ ) by Quality Controlled Biochemicals, Inc. (Hopkinton, MA, USA). Peptide stock solutions were prepared in dimethylsulfoxide (DMSO) (spectroscopy grade).

Vesicles were prepared according to two different protocols. For the preparation of small unilamellar vesicles (SUV) dried lipid films were dispersed in buffer, $5 \mathrm{mM}$ HEPES, $100 \mathrm{mM} \mathrm{NaCl}(\mathrm{pH} 7.4)$ and sonicated with a probe sonicator. Large unilamellar vesicles (LUV) were prepared following the extrusion method of Hope et al. [12] in $5 \mathrm{mM}$ HEPES, $100 \mathrm{mM} \mathrm{NaCl}$ (pH 7.4) buffer. Lipid concentrations of liposome suspensions were determined by phosphate analysis [13].

Leakage and membrane-mixing measurements were conducted at $37^{\circ} \mathrm{C}$ in thermostatically controlled cuvettes using a Perkin-Elmer LS50-B spectrofluorometer. The medium in the cuvettes was continuously stirred to allow the rapid mixing of peptide and vesicles. Release of vesicular contents to the medium was monitored by the ANTS/DPX assay. LUV containing $12.5 \mathrm{mM}$ ANTS, $45 \mathrm{mM}$ DPX, $20 \mathrm{mM} \mathrm{NaCl}$ and $5 \mathrm{mM}$ HEPES [14] were obtained by separating the unencapsulated material by gel filtration in a Sephadex G-75 column eluted with $5 \mathrm{mM}$ HEPES, $100 \mathrm{mM} \mathrm{NaCl}$ (pH 7.4). Osmolarities were adjusted to 200 mosm in a cryoscopic osmometer (Osmomat 030, Gonotec, Berlin, Germany). Fluorescence measurements were performed by setting the ANTS emission at $520 \mathrm{~nm}$ and the excitation at $355 \mathrm{~nm}$. A cutoff filter $(470 \mathrm{~nm})$ was placed between the sample and 
the emission monochromator. The $0 \%$ leakage corresponded to the fluorescence of the vesicles at time zero; $100 \%$ leakage was the fluorescence value obtained after addition of Triton X-100 $(0.5 \% \mathrm{v} / \mathrm{v})$. Final extent values of leakage were obtained at times at which the kinetics of the process leveled off. Membrane lipid mixing was monitored using the resonance energy transfer (RET) assay, described by Struck et al. [15]. The assay is based on the dilution of $N$-NBD-PE and $N$-Rho-PE. Dilution due to membrane mixing results in an increase in $N$-NBD-PE fluorescence. Vesicles containing $0.6 \mathrm{~mol} \%$ of each probe were mixed with unlabeled vesicles at 1:4 ratio. The NBD emission was monitored at $530 \mathrm{~nm}$ with the excitation wavelength set at $465 \mathrm{~nm}$. A cutoff filter at $515 \mathrm{~nm}$ was used between the sample and the emission monochromator to avoid scattering interferences. The fluorescence scale was calibrated such that the zero level corresponded to the initial residual fluorescence of the labeled vesicles and the $100 \%$ value to complete mixing of all the lipids in the system. The latter value was set by the fluorescence intensity of vesicles, labeled with $0.12 \mathrm{~mol} \%$ each of the fluorophores, at the same total lipid concentration as in the fusion assay.

Partitioning isotherms were performed by monitoring the fractional change in emitted Trp fluorescence of $\mathrm{EBO}_{\mathrm{GE}}$ titrated with increasing lipid concentrations. Fluorescence was recorded in a Perkin-Elmer MPF-66 spectrofluorometer with excitation and emission monochromators set at 280 and $348 \mathrm{~nm}$ respectively and the corresponding slits at 2.5 and $10 \mathrm{~nm}$. The signal was further corrected for dilution and inner filter effects as described in [16] using the soluble Trp analog NATA unable to partition into membranes.

Circular dichroism (CD) measurements were carried out on a Jobin Yvon CD6 circular dichroism spectropolarimeter (CD-Longjumeau, France) calibrated routinely with isoandrosterone. The spectra were measured in a $1 \mathrm{~mm}$ path-length quartz cell. Data were taken with a $0.2 \mathrm{~nm}$ step size, $8 \mathrm{~s}$ average time, $20 \mathrm{~nm} / \mathrm{min}$ speed, and the results of 10 scans were averaged. $\mathrm{CD}$ spectra were taken at $25^{\circ} \mathrm{C}$, in $5 \mathrm{mM}$ MOPS buffer, pH 7 in the presence of $100 \mathrm{mM} \mathrm{NaCl}$. Peptide concentration was $40 \mu \mathrm{M}$ as determined by ultraviolet (UV) spectroscopy using $\varepsilon_{280}=7050 \mathrm{M}^{-1} \mathrm{~cm}^{-1}$ from the contribution to the UV spectrum of tryptophan and tyrosine [17].

Infrared spectroscopy (IR) measurements were essentially conducted as in [18]. Samples in presence of vesicles consisted of floated peptide-lipid complexes obtained in $\mathrm{D}_{2} \mathrm{O}$ buffer after ultracentrifugation. Solvent samples were also obtained from the supernatant fraction not containing lipid or peptide and subsequently used as background controls. Infrared spectra were recorded in a Nicolet 520 spectrometer equipped with an MCT detector. Samples were placed between two $\mathrm{CaF}_{2}$ windows separated by $50 \mu \mathrm{m}$ spacers. 500 scans (sample) and 500 scans (reference) were taken for each spectrum, using a shuttle device. Spectra were transferred to a personal computer where solvent subtraction and band position determinations were performed as previously reported [19]. Curve-fitting of the original amide I band was carried out with the GRAMS software (Galactic Corp.). The area under each peak was used to calculate the percentage of each component and finally to estimate the percentage of secondary structure components. The estimated errors are $\pm 1 \mathrm{~cm}^{-1}$ for the band position and $\pm 5 \%$ for the peak area [19].

\section{Results}

It has been reported [10] that inclusion of anionic PI in the bilayer composition promoted binding of $\mathrm{EBO}_{\mathrm{GE}}$ to vesicles. In addition, calcium was necessary to observe $\mathrm{EBO}_{\mathrm{GE}}$-mediated fusion of vesicles. Results in Fig. 1 demonstrate that $\mathrm{EBO}_{\mathrm{GE}}$-induced permeabilization and fusion of PI membranes appear to be mutually exclusive processes and that calcium governs which of the two will prevail in a given situation. Peptide addition to a suspension of PI vesicles in the absence of $\mathrm{Ca}^{2+}$ induced extensive efflux of aqueous contents to the medium (Fig. 1A, curve a). However, the ongoing leakage process could be arrested by addition of calcium (curve b). Moreover, when the cation was present in the PI vesicle sample buffer, peptide addition induced negligible leakage (curve c). Fig. $1 \mathrm{~B}$ shows the influence of $\mathrm{Ca}^{2+}$ concentration on pep- tide-induced leakage. 50\% inhibition was observed for ca. 0.1 $\mathrm{mM}$ calcium concentration, and inhibition (ca. 90\%) was maximum above $1.0 \mathrm{mM}$. Leakage inhibition correlated with promotion by the cation of peptide-induced inter-vesicle mixing of lipids (Fig. 1C). Thus calcium modulated two dissimilar
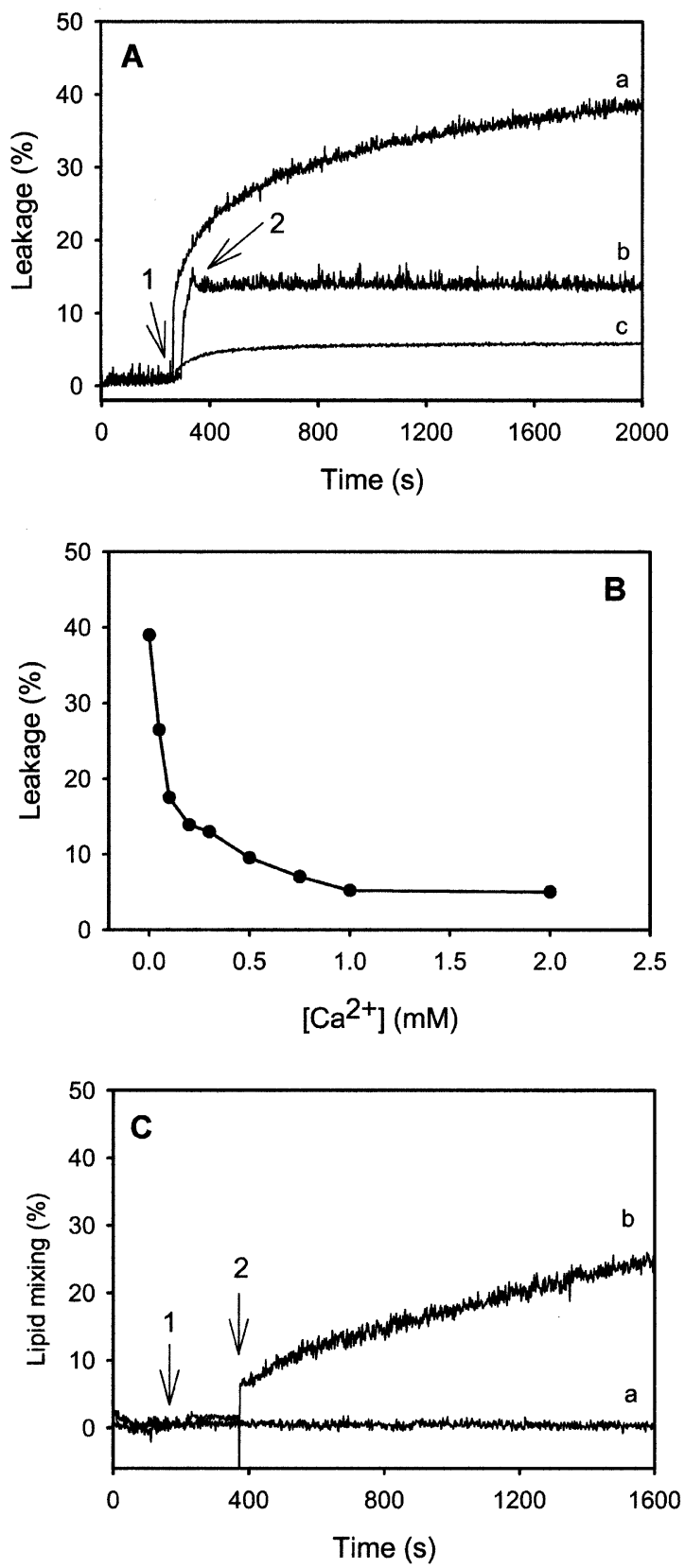

Fig. 1. $\mathrm{EBO}_{\mathrm{GE}}$ peptide-induced leakage of contents (ANTS/DPX assay) and fusion (membrane lipid mixing, RET assay) of PI LUV. A: Kinetics of leakage and effect of calcium addition. (a) Control assay in absence of the cation, the peptide was added at the time indicated by arrow ' 1 '; (b) the cation was added after the onset of the process at the time indicated by arrow '2'; (c) the cation was present before the addition of the peptide. The peptide was added at the peptide to lipid mole ratio of $1: 5$ and final calcium concentration was $5 \mathrm{mM}$. B: Effect of increasing calcium concentrations on the final extents of $\mathrm{EBO}_{\mathrm{GE}}$-induced leakage (added peptide to lipid mole ratio of 1:5). C: Mixing of lipids as a function of time. (a) and (b) As in the previous panel. Lipid concentration was 100 $\mu \mathrm{M}$ in all cases. 


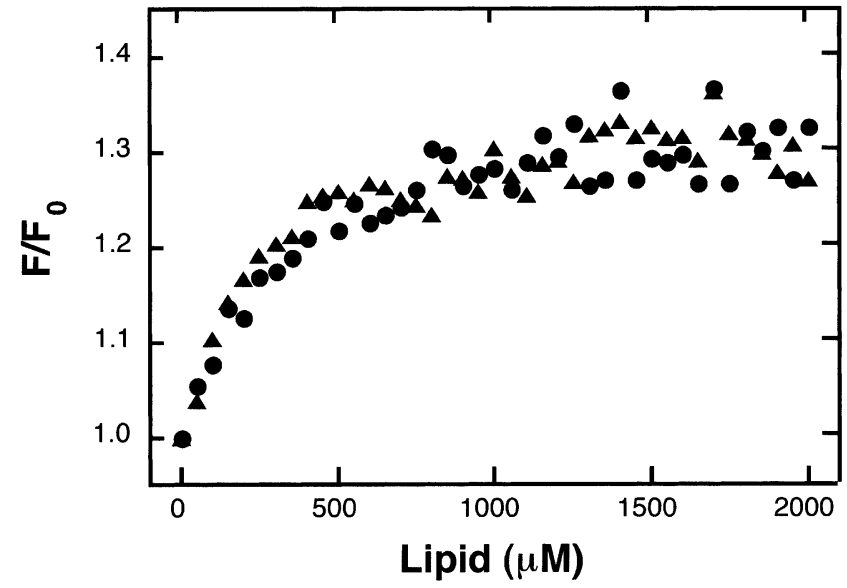

Fig. 2. Partitioning of $\mathrm{EBO}_{\mathrm{GE}}$ from water into membranes. Partitioning was estimated from Trp fluorescence changes in the presence of increasing concentrations of PC:PI $(1: 2$, mole ratio) SUV in absence $(\boldsymbol{)})$ or presence of $5 \mathrm{mM}$ calcium $(\boldsymbol{\Delta})$. The soluble Trp ana$\log$ NATA was used to obtain a reference curve corresponding to $0 \%$ binding. Peptide concentration in all cases was $0.25 \mu \mathrm{M}$.

vesicle perturbing effects of the peptide. In what follows additional evidence will be provided indicating that these processes were promoted by the same amount of membrane-bound peptide. However, the structures adopted by the peptide in the membrane were different.

The water-membrane peptide partition equilibrium was next characterized under conditions allowing each of the two mutually exclusive processes to evolve (Fig. 2). Association of $\mathrm{EBO}_{\mathrm{GE}}$ to PC:PI (1:2 mole ratio) SUV in the absence of $\mathrm{Ca}^{2+}$ had been previously evaluated at a fixed lipid concentration by physically separating solution-free and lipidbound fractions by centrifugation (table 2 in [10]). In addition, the amount of lipid-bound peptide was estimated in the same intact system using a resonance energy transfer assay. Here, this partition equilibrium was further characterized by constructing the partition isotherm [16]. Self-aggregation in solution due to its hydrophobic character may interfere with peptide incorporation into target membranes, a fact that precludes the experimental characterization of the watermembrane peptide partitioning equilibrium. In a control experiment, it was shown by $C D$ spectroscopy that, in the micromolar concentration range used to measure partitioning, $\mathrm{EBO}_{\mathrm{GE}}$ remained unfolded and non-aggregated for hours in solution. Thus, peptide self-aggregation that might interfere with peptide incorporation into target membranes could be obviated as a source of error under our experimental conditions.

The partition coefficient was evaluated by monitoring the increase of the Trp fluorescence emission intensity when lipid vesicles were added to $\mathrm{EBO}_{\mathrm{GE}}$. The apparent mole fraction partition coefficients, $K_{\mathrm{x}}$, were determined by fitting the experimental values (circles in Fig. 2) to a hyperbolic function. From the corresponding curve an apparent partition coefficient $K_{\mathrm{x}} \sim 2.6 \times 10^{5}$ was computed. Similar values for this parameter $\left(0.5 \times 10^{5}\right.$ and $\left.1.1 \times 10^{5}\right)$ had been obtained using different methods, at a fixed lipid concentration of $0.5 \mathrm{mM}$ [10]. Results in Fig. 2 also demonstrate that the presence of calcium does not affect the partition equilibrium (triangles). Thus, the possibility that $\mathrm{Ca}^{2+}$-triggered fusion (Fig. 1) was due to a massive peptide binding to vesicles could be ruled out. Possi- ble conformational changes that would explain the different perturbing effects of the peptide were next examined by spectroscopic techniques under various experimental conditions.

The conformation of the peptide in solution was first characterized by $\mathrm{CD}$ spectroscopy. As mentioned above, the CD spectrum in buffer solution $(100 \mathrm{mM} \mathrm{NaCl})$ indicated a random coil conformation for the peptide (Fig. 3). This conformation was independent of the ionic strength of the medium as demonstrated by the lack of conformational change when the peptide solution was titrated with $\mathrm{NaCl}$ up to a $1 \mathrm{M}$ final salt concentration. No significant changes were observed either for the peptide in buffer solution in the presence of $1 \mathrm{mM}$ $\mathrm{CaCl}_{2}$. Consistent with these observations the AGADIR program [20] predicts an extremely low helical content $(<5 \%)$ in neat aqueous solution (data not shown).

A decrease in peptide environmental polarity occurs when the peptide is transferred from water to membrane interfaces. The effect of polarity on peptide conformation can be studied by using aqueous mixtures of methanol or TFE. In both cases, the polarity of the medium decreases, however only TFE can induce periodic secondary structure by promoting intramolecular hydrogen bond formation [21-23]. Thus, in the presence of $20 \%$ methanol the peptide remained in a random coil conformation (not shown), while in the presence of $20 \%$ TFE the CD spectrum of the peptide already showed a negative band at $222 \mathrm{~nm}$ (Fig. 3), suggesting the adoption of an $\alpha$-helical conformation. Increasing concentrations of TFE induced a further helical stabilization (Fig. 3). In contrast, in the presence of $60 \%$ methanol the peptide displayed a dominant random coil conformation. The helical conformation induced by TFE was independent of the salt content in the buffer, indeed the TFE titration profiles in a buffer containing no $\mathrm{NaCl}$ (not shown) were almost superimposable to those obtained in the presence of $100 \mathrm{mM} \mathrm{NaCl}$ shown in Fig. 3. The data altogether suggest that the peptide contains a particular sequence of amino acids that, in a suitably non-polar environment, can adopt an $\alpha$-helical conformation. We dismissed the use of $\mathrm{CD}$ for characterizing the membrane-bound structures of $\mathrm{EBO}_{\mathrm{GE}}$ because PI vesicles in the presence of $\mathrm{Ca}^{2+}$ readily

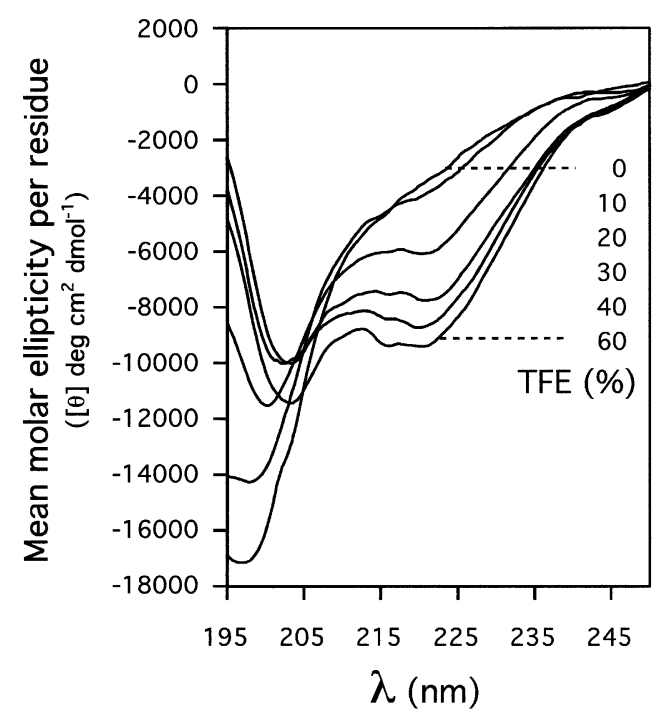

Fig. 3. Far UV CD spectra of $\mathrm{EBO}_{\mathrm{GE}}$ in the presence of increasing TFE percentages. Spectra values are expressed as mean molar ellipticity per residue. Peptide concentration was $40 \mu \mathrm{M}$. 
aggregated giving rise to cloudy dispersions. These samples were not appropriate for CD measurements.

Light scattering effects do not significantly distort the IR spectrum. For evaluating peptide conformation in concentrated and aggregated lipid samples this represents a technical advantage. Thus, IR assays were performed to determine the conformation adopted by $\mathrm{EBO}_{\mathrm{GE}}$ not only in buffer and trifluoroethanol but also in the presence of vesicles (Fig. 4 and Table 1). In $\mathrm{D}_{2} \mathrm{O}$ buffer the IR spectra of $\mathrm{EBO}_{\mathrm{GE}}$ in the amide I region (data not shown) revealed the presence of several absorption bands (centered at $1639 \mathrm{~cm}^{-1}$ ), characteristic of unordered conformations while addition of TFE shifted the absorption maximum to bands (centered at $1646 \mathrm{~cm}^{-1}$ ), associated with fully accessible $\alpha$-helical conformations in deuterated media [24]. Therefore, in good agreement with CD data, IR described a mainly unordered to helical conformational transition induced by TFE.

In the presence of lipid vesicles, the conformation of membrane-bound peptide (isolated by flotation) was sensitive to the experimental conditions (Fig. 4). In the absence of calcium (Fig. 4A, see inset), exposure to the bilayer milieu promoted folding of the sequence into a mainly $\alpha$-helical secondary structure characterized by an absorption maximum of the amide I band at $1652 \mathrm{~cm}^{-1}$. The data in Table 1 indicate that membrane association in the absence of calcium increases the $\alpha$-helical content of the peptide. Assuming that the proportion of $\alpha$-helical conformation for the peptide in solution

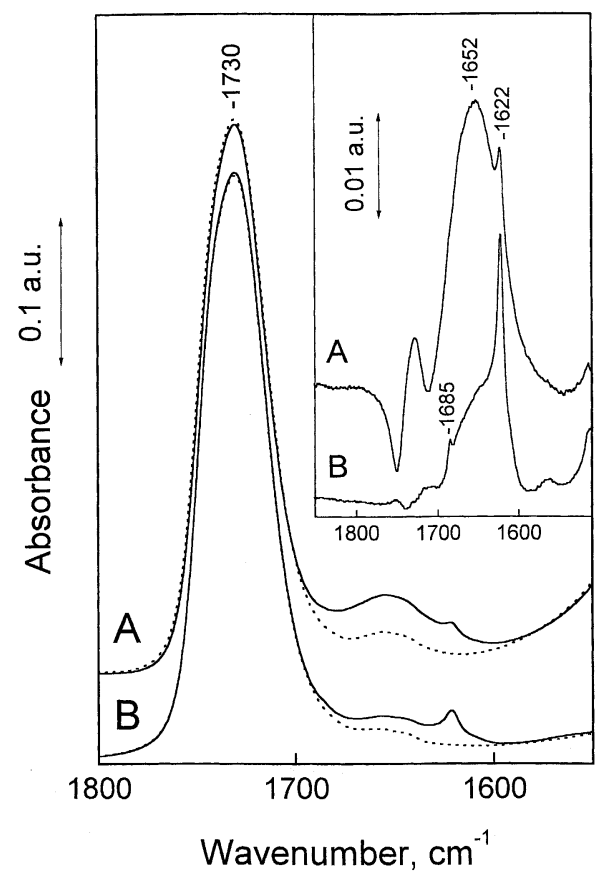

Fig. 4. IR spectra of $\mathrm{EBO}_{\mathrm{GE}}$ bound to PC:PI $(1: 2)$ vesicles. The peptide (added peptide to lipid ratio, 1:17), was mixed with lipid vesicles $(1 \mathrm{mM})$ and peptide-lipid complexes were subsequently isolated from the floating fractions after ultracentrifugation in $\mathrm{D}_{2} \mathrm{O}$ buffer. A represents the spectrum of a sample in absence of calcium. B corresponds to an aliquot of sample A incubated with $10 \mathrm{mM}$ calcium for $30 \mathrm{~min}$ before being subjected to flotation. Spectra in the inset were obtained after subtracting from the signal of peptidelipid samples (continuous curves) the one arising from pure lipid samples treated similarly (dotted curves). Side-lobes in spectrum A are due to small changes in the carbonyl lipid vibration at 1730 $\mathrm{cm}^{-1}$ upon peptide partitioning.
Table 1

Band components of IR spectra displayed in the inset of Fig. 4

\begin{tabular}{llrllc}
\hline Peak & \multicolumn{1}{l}{-calcium $(\mathrm{A})$} & & & $+10 \mathrm{mM}$ calcium $(\mathrm{B})$ \\
\cline { 2 - 3 } \cline { 5 - 5 } & Center $\left(\mathrm{cm}^{-1}\right)$ & Area $(\%)$ & & Center $\left(\mathrm{cm}^{-1}\right)$ & Area $(\%)$ \\
\hline 1 & 1687 & $3 \pm 1$ & & 1686 & $4 \pm 2$ \\
2 & 1671 & $28 \pm 4$ & & 1670 & $24 \pm 3$ \\
3 & 1652 & $43 \pm 4$ & & 1646 & $27 \pm 3$ \\
4 & 1638 & $5 \pm 2$ & & $1626+1622$ & $44 \pm 5$ \\
5 & 1623 & $21 \pm 3$ & & \\
\hline
\end{tabular}

is negligible, the percentage area estimated for the $\alpha$-helical component $(43 \pm 4 \%)$ would be consistent with $\sim 7$ residues changing from an unordered to an $\alpha$-helical conformation.

Results in Fig. 1 show that the presence of calcium, added either before or after the peptide, was necessary to observe $\mathrm{EBO}_{\mathrm{GE}}-$ mediated fusion of vesicles. Neither the peptide alone nor the cation on its own were capable of triggering the process. The structural characterization revealed that this synergy may be due to an effect of calcium on the organization of the membrane-associated peptide. IR data in Fig. 4 show that addition of calcium to vesicles containing $\mathrm{EBO}_{\mathrm{GE}}$ induces a structural transition from the $\alpha$-helical conformation to a predominantly extended ( $\beta$-type) structure. This conformational rearrangement is evidenced by a shift of the amide $\mathrm{I}$ band absorption maximum from $1652 \mathrm{~cm}^{-1}$ (A) to $1622 \mathrm{~cm}^{-1}$ (B), upon addition of calcium to the same lipid-peptide complexes (Fig. 4, inset). This fact, together with the presence of the high-frequency component at $1685 \mathrm{~cm}^{-1}$ (see also Table $1)$, suggests that the peptide might adopt an extended antiparallel $\beta$-structure under these conditions [24].

\section{Discussion}

In most viral fusion events the hydrophobic fusion peptide, usually located at the N-terminal end of the fusogenic subunit, is thought to be involved in driving the initial partitioning of the viral fusion protein into the target cell membrane [25], and also to participate actively in the formation of a functional fusion pore (for reviews see [25-28]). The mechanisms governing the direct interactions between these viral glycoprotein fragments and the membrane lipids are thought to be essential in understanding their fusogenic activity. N-terminal fusion peptides, such as those derived from influenza or human immunodeficiency virus fusion proteins, have been shown to transfer spontaneously to membranes, to generate bilayer perturbations leading to permeabilization and fusion, and to be conformationally polymorphic as membrane-associated species, a phenomenon that has been related to their high content of Gly and Ala residues [25-28]. Thus, unlike classical transmembrane anchors, fusion peptides inserted into target membranes might adopt different conformations including helical monomers penetrating in an oblique angle into one monolayer $[26,29,30]$, helical aggregates assembling transmembrane lytic pores [31] and aggregates of extended strands producing local dehydration and monolayer surface expansion [18,28,31-35]. Inter-conversion between the different conformational states appears dictated by the peptide membrane surface density $[28,33]$, the lipid composition $[18,31]$ and the monolayer lateral pressure [36]. This conformational flexibility appears to be functionally meaningful since mutations affecting the fusion capacity of the proteins have been shown to interfere 
with the conformational state of the membrane-bound fusion peptides [32,37-39].

In contrast to $\mathrm{N}$-terminal fusion peptides, internal fusion peptides are poorly characterized in their interactions with membranes. Delos et al. [40,41] have approached the issue of internal fusion peptides and their structure-function relationships. According to these authors, internal fusion peptides are segmented following a common structural motif, namely two ordered regions intervened by a turn or a loop, usually containing one or more Pro residues. Maintenance of this organization appears to be fundamental for the formation of the native (metastable) fusion protein structure, as well as for the membrane interactions that lead to fusion. In this study we have characterized the ability of the internal fusion peptide of Ebola glycoprotein to associate with membranes. Our data reveal that, similarly to N-terminal fusion peptides, internal Ebola fusion peptide perturbs bilayers inducing permeabilization and fusion, and that these processes appear mediated by distinct conformations adopted in membranes. However, in contrast to the former cases, we found effective incorporation of this internal sequence only when a particular phospholipid, PI, was present in the membrane composition.

Partition of $\mathrm{EBO}_{\mathrm{GE}}$ into membranes may be discussed in the context of current knowledge on interfacial partitioning energetics $[42,43]$. Considering $\mathrm{EBO}_{\mathrm{GE}}$ as an electrically neutral species, computation of the experimental free energy of partitioning $\left(\Delta G_{\exp }=-R T \ln K_{\mathrm{x}}\right)$ gives an estimate of ca. -7.0 $\mathrm{kcal} \mathrm{mol}^{-1}$. Our IR data are consistent with the adoption by approximately one-half of the $\mathrm{EBO}_{\mathrm{GE}}$ sequence (ca. seven to eight residues) of a defined secondary conformation upon entering the membrane environment. Experimental evaluation indicated that $\Delta G_{\text {if }}$, the per-residue free energy change upon folding into membranes, is about $-0.5 \mathrm{kcal} \mathrm{mol}^{-1}[42,43]$. Thus, the free energy change upon $\mathrm{EBO}_{\mathrm{GE}}$ folding into membrane interfaces, $\Delta G_{\text {if }}$, would be in the range of -3.5 to -4.0 $\mathrm{kcal} \mathrm{mol}^{-1}$. We may conclude that spontaneous partitioning of $\mathrm{EBO}_{\mathrm{GE}}$ into bilayers is greatly influenced by the ability of the sequence to fold adopting a defined secondary structure.

The important contribution of conformational energy probably explains why $\mathrm{EBO}_{\mathrm{GE}}$ did not partition in pure PC: the peptide was incapable of adopting a defined secondary structure in PC membranes. In addition, the peptide did not exhibit any conformational change either when titrated with mixed micelles of $n$-octyl- $\beta$-D-glucopyranoside or $n$-heptyl- $\beta$ D-glucopyranoside and PI (data not shown). These findings are consistent with the absence of stereospecific interactions of the peptide with inositol moieties that would promote intramembrane folding of this sequence. Taking into account that the acyl chain compositions of the PI and PC used in this study were similar, it is tempting to speculate that $\mathrm{EBO}_{\mathrm{GE}}$ partitioning into PI-containing membranes depends on a structural role of the PI headgroup at the bilayer interface. The intricate H-bonding network at the surface of PI-enriched bilayers [44] may stabilize the unfolded partitioned peptide, thus facilitating its transfer to less polar regions of the bilayer, and its concomitant folding.

The present study shows that Ebola internal fusion peptide may alternate conformations when bound to membranes. The $\mathrm{EBO}_{\mathrm{GE}}$ sequence contains three Gly and five Ala residues, which already suggests certain conformational flexibility. The peptide was actually found to exist in two different structures in vesicles, one in the absence of calcium, that supports
ANTS/DPX leakage but inhibits fusion, and one in the presence of the cation in which the peptide supports mixing of lipids and inhibits efflux (Fig. 1). In the absence of the cation the peptide was predominantly found in an $\alpha$-helix conformation, whereas in its presence the structure changed to a mainly extended antiparallel $\beta$-structure (Fig. 4 and Table 1). $\mathrm{Ca}^{2+}$ at millimolar concentrations will certainly bind the negatively charged PI headgroups, with the result that PI-rich domains in the target membrane will remain highly polar, but with a smaller negative electric charge, and with a reorganized $\mathrm{H}$-bonding network. Those changes may well explain the different peptide secondary structures that are stabilized at the membrane-water interface in the presence and absence of the cation.

Thus, our structural characterization provides some insights into the role of calcium as a co-promoter of fusion together with the peptide. The cation-promoted $\beta$-type peptide structure, or a transient intermediate, appears to cause the sort of membrane perturbations required for vesicle fusion. It is possible that the conformational polymorphism of the inserted fusion peptide contributes to the flexibility of the fusogenic complex by adapting to configurations that can be either perpendicular or parallel to the target bilayer plane $[45,46]$. In addition, membrane perturbations induced by peptides interacting with the target membrane at the point of fusion might promote distortion as proposed by Weissenhorn et al. [45]. During GP2-induced fusion, the target membrane perturbation induced by the fusion peptide will be localized at the point of fusion, and subsequently propagate into the closely appositioned virion membrane.

Finally, we must caution here that our studies in model PI membranes focus on unraveling the structural determinants (in the fusion peptide and in the target bilayers) required to sustain a perturbing interaction. An interaction that leads to a general disorganization of the bilayer architecture is postulated to evolve during membrane merger. How these requirements are provided in the context of the full glycoprotein interacting with the endosomal membrane, where filoviruscell fusion probably takes place, is at the present unknown. In this regard, it is important to note that glycosylated forms of PI might be quantitatively important in specialized lipid domains of those membranes [47].

Acknowledgements: The authors gratefully acknowledge Professor José L.R. Arrondo and Dr. José M. Martínez-Caaveiro for helpful discussions. This work was supported by MCyT (EET 2001/1954; BMC2000-1448), the Basque Government (EX-1998-28; PI-1998-32), the Generalitat Valenciana (GV00-040) and the University of the Basque Country (UPV 042.310-EA085/97; UPV 042.310-G03/98). T.S. was supported by the Basque Government

\section{References}

[1] Murphy, F.A., Kiley, M.P. and Fisher-Hoch, S.P. (1990) in: Virology (Fields, B.N., Knipe, D.M. et al., Eds.), pp. 933-942, Raven Press, New York.

[2] Sanchez, A., Trappier, S.G., Mahy, B.W.J., Peters, C.J. and Nichol, S.T. (1996) Proc. Natl. Acad. Sci. USA 93, 3602-3607.

[3] Sanchez, A., Yang, Z., Xu, L., Nabel, G.J., Crews, T. and Peters, C.J. (1998) J. Virol. 72, 6442-6447.

[4] Volchkov, V.E. (1999) Curr. Top. Microbiol. Immunol. 235, 35 47.

[5] Feldmann, H., Volchkov, V.E., Volchkova, V.A. and Klenk, H.D. (1999) in: 100 Years of Virology (Calisher, C.H. and Horzinek, M.C., Eds.), pp. 159-169, Springer, Wien. 
[6] Takada, A., Robison, C., Goto, H., Sanchez, A., Gopal, K., Whitt, M.A. and Kawaoka, Y. (1997) Proc. Natl. Acad. Sci. USA 94, 14764-14769.

[7] Wool-Lewis, R.J. and Bates, P. (1998) J. Virol. 72, 3155-3160.

[8] Wool-Lewis, R.J. and Bates, P. (1999) J. Virol. 73, 1419-1426.

[9] Gallaher, W.R. (1996) Cell 85, 477-478.

[10] Ruiz-Argüello, M.B., Goñi, F.M., Pereira, F.B. and Nieva, J.L. (1998) J. Virol. 72, 1775-1781.

[11] Ito, H., Watanabe, S., Sanchez, A., Whitt, M.A. and Kawaoka, Y. (1999) J. Virol. 73, 8907-8912.

[12] Hope, M.J., Bally, M.B., Webb, G. and Cullis, P.R. (1985) Biochim. Biophys. Acta 812, 55-65.

[13] Bottcher, C.S.F., van Gent, C.M. and Fries, C. (1961) Anal. Chim. Acta 24, 203-204.

[14] Ellens, H., Bentz, J. and Szoka, F.C. (1985) Biochemistry 24, 3099-3106.

[15] Struck, D.K., Hoekstra, D. and Pagano, R.E. (1981) Biochemistry 20, 4093-4099.

[16] White, S., Wimley, W.C., Ladokhin, A.S. and Hristova, K. (1998) Methods Enzymol. 295, 62-87.

[17] Chakrabartty, A., Kortemme, T., Padmanabhan, S. and Baldwin, R.L. (1993) Biochemistry 32, 5560-5565

[18] Pereira, F.B., Goñi, F.M., Muga, A. and Nieva, J.L. (1997) Biophys. J. 73, 1977-1986.

[19] Arrondo, J.L.R., Castresana, J., Muga, A. and Goñi, F.M (1993) Prog. Biophys. Mol. Biol. 59, 23-56.

[20] Muñoz, V. and Serrano, L. (1997) Biopolymers 41, 495-509.

[21] Blondelle, S.E., Ostresh, J.M., Houghten, R.A. and Pérez-Payá, E. (1995) Biophys. J. 68, 351-359.

[22] Luo, P. and Baldwin, R.L. (1997) Biochemistry 36, 8413-8421.

[23] Buck, M. (1998) Q. Rev. Biophys. 31, 297-355.

[24] Arrondo, J.L.R. and Goñi, F.M. (1999) Prog. Biophys. Mol. Biol. 72, 367-405.

[25] White, J. (1992) Science 258, 917-923.

[26] Durell, S.R., Martin, I., Ruysschaert, J., Shai, Y. and Blumenthal, R. (1997) Mol. Membr. Biol. 14, 97-112.

[27] Nir, S. and Nieva, J.L. (2000) Prog. Lipid Res. 39, 181-206.

[28] Han, X. and Tamm, L.K. (2000) Biosci. Rep. 20, 501-518.

[29] Brunner, J. (1989) FEBS Lett. 257, 369-372.
[30] Han, X., Bushweller, J.H., Cafiso, D.S. and Tamm, L.K. (2001) Nat. Struct. Biol. 8, 715-720.

[31] Nieva, J.L., Nir, S., Muga, A., Goñi, F.M. and Wilschut, J. (1994) Biochemistry 33, 3201-3209.

[32] Gray, C., Tatulian, S.A., Wharton, S.A. and Tamm, L.K. (1996) Biophys. J. 70, 2275-2286.

[33] Mobley, P.W., Waring, A.J., Sherman, M.A. and Gordon, L.M. (1999) Biochim. Biophys. Acta 1418, 1-18.

[34] Agirre, A., Flach, C., Goñi, F.M., Mendelsohn, R., Valpuesta, J.M., Wu, F. and Nieva, J.L. (2000) Biochim. Biophys. Acta $1467,153-164$.

[35] Yang, J., Gabrys, C.M. and Weliky, D.P. (2001) Biochemistry $40,8126-8137$.

[36] Schwarz, G. and Taylor, S.E. (1999) Biophys. J. 76, $3167-$ 3175.

[37] Rafalski, M., Ortiz, A., Rockwell, A., van Ginkel, L.C., Lear, J.D., DeGrado, W.F. and Wilschut, J. (1991) Biochemistry 30, 10211-10220.

[38] Pereira, F.B., Goñi, F.M. and Nieva, J.L. (1995) FEBS Lett. 362, 243-246.

[39] Kliger, Y., Aharon, A., Rapaport, D., Jones, P., Blumenthal, R. and Shai, Y. (1997) J. Biol. Chem. 272, 13496-13505.

[40] Delos, S.E., Gilbert, J.M. and White, J.M. (2000) J. Virol. 74, 1686-1693.

[41] Delos, S.E. and White, J.M. (2000) J. Virol. 74, 9738-9741.

[42] Wimley, W.C., Hristova, K., Ladokhin, A.S., Silvestro, L., Axelsen, P.H. and White, S.H. (1998) J. Mol. Biol. 277, 10911110.

[43] Ladokhin, A.S. and White, S.H. (1999) J. Mol. Biol. 285, $1363-$ 1369.

[44] Zhou, C., Horstman, D., Carpenter, G. and Roberts, M.F. (1999) J. Biol. Chem. 274, 2786-2793.

[45] Weissenhorn, W., Carfi, A., Lee, K., Skehel, J.J. and Wiley, D.C. (1998) Mol. Cell 2, 605-616.

[46] Malashkevich, V.N., Schneider, B.J., McNally, M.N., Milhollen, M.A., Pang, J.X. and Kim, P.S. (1999) Proc. Natl. Acad. Sci. USA 96, 2662-2667.

[47] Singh, N., Liang, L.N., Tycocinski, M.L. and Tartakoff, A.M. (1996) J. Biol. Chem. 271, 12879-12884. 